Revista do CESP, Belo Horizonte, v.34, n.52, p. 135-162, 2014

\title{
O olhar responsável e a ética da comunicabilidade na poesia portuguesa pós-modernista
}

\section{The responsible look and the ethic of communicability in postmodern Portuguese poetry}

Joana Matos Frias

Faculdade de Letras da Universidade do Porto, Porto, Lisboa, Portugual jfrias@netcabo.pt

Resumo: Reconstituição histórico-crítica dos principais aspectos humanistas e interventivos da poesia e da poética de Ruy Cinatti e dos poetas reunidos em torno dos Cadernos de Poesia. O ensaio pretende identificar e reflectir sobre os processos testemunhais da poesia portuguesa dos anos 40-50 do século XX, a partir da leitura de textos programáticos dos autores mais decisivos da época.

Palavras-chave: Cinatti; Sena; Cadernos de Poesia; poesia social.

Abstract: Historical-critical reconstitution of the main aspects humanist and interventional of poetry and the poetic of Ruy Cinatti and others poets gathered around Cadernos de Poesia. The essay intends to identify and reflect about the witness's process of Portuguese poetry of the decade of 1940-1950 of XX century, from the reading programmatic texts of the most decisive authors of the time.

Keywords: Cinatti; Sena; Cadernos de Poesia; Social Poetry;

Recebido em 06 de julho de 2014. Aprovado em 19 de outubro de 2014. 
7 m 1953, Ruy Cinatti escrevia a Jorge de Sena, apontando Rimbaud como "o esqueleto sobre o qual eu 'pranto', camada após camada, substância de natureza virgiliana, quer do próprio, quer de outros afins". Fazia-o, sobretudo, para glorificar Virgílio, porque ao poeta latino devia "a santa realidade de que fala Claudel, ou o andar ainda de pés fincados na terra". ${ }^{1}$ A passagem a que Cinatti alude encontra-se num ensaio de Paul Claudel sobre Dante, onde, numa reflexão crítica em torno de Baudelaire, o autor das Cinco Grandes Odes acusa o poeta das Flores do Mal de pretender evadir-se do mundo. Eis a argumentação de Claudel:

O objecto da poesia não é, como muitas vezes se diz, os sonhos, as ilusões ou as ideias. É esta santa realidade, dada de uma vez por todas, no centro da qual nos encontramos situados. É o universo das coisas visíveis, ao qual a Fé acrescenta o das coisas invisíveis. É tudo aquilo que nos olha e que nós olhamos. ${ }^{2}$

A "santa realidade" festejada por Cinatti, equivalente ao acto de "andar de pés fincados na terra", outra coisa não era, pois, do que a realidade vivida por um homem em situação, localizado num ponto preciso da curvatura do espaçotempo - homem circunstancial, cuja existência se define com base nesse ponto entendido como autêntico ponto de vista, uma vez que a "santa realidade" se resume enfim a "tudo aquilo que nos olha e que nós olhamos", a partir da nossa posição centrífuga e centrípeta. É aqui mesmo que reside o "real absoluto" da poesia no entender de Cinatti, conforme havia expresso ao mesmo Jorge de Sena em 1941, ano de publicação do seu primeiro livro de poemas:

[...] a poesia é o real absoluto de todos nós (poesia no sentido claudeliano), como que uma integração do universo no poeta e logo jorros de luz para fora do poeta. ${ }^{3}$

Quer dizer, "andar de pés fincados na terra", ou estar no mundo, alicerce de toda a condição humana que Cinatti sempre procurou exprimir,

${ }^{1}$ CINATTI apud STILWELL, 1995, 243. Carta inédita datada de 27 de julho de 1953. ${ }^{2}$ CLAUDEL, 1938, 165.

${ }^{3}$ CINATTI apud STILWELL, 1995, p. 243. Carta a Jorge de Sena, datada de abril de 1941. Significativamente, já aqui Cinatti enuncia o intertexto de Novalis à luz da poética de Claudel, ou seja, submetendo-o a uma radical metamorfose (ver NOVALIS, 1992, p. 69). 
implica antes de mais abdicar da solidão para viver em comunhão, sendo aí que reside, no entender do poeta, a base de qualquer "ética poética": "O poema / imprime / convívio", apregoa no livro póstumo Archeologia ad Usum Animae. ${ }^{4}$

Na senda ainda de Claudel, o primeiro passo fulcral deste convívio traduz-se na simples troca de olhares, condição sine qua non da dissolução definitiva do Outro no Mesmo, que Cinatti virá a apreciar no verso do próprio Dante, de inspiração bíblica, "ed eran due in uno e uno in due", já então escolhido por Ezra Pound para epígrafe da Parte III do seu "Near Perigord", composto em 1915. Nesse sentido, para Cinatti, o próximo é, nos seus próprios termos de raiz católica e cristã, "a eterna questão", conforme explicita no título do poema "A eterna questão: o próximo", do livro O tédio recompensado (1968), onde podemos ler:

Ouves, não ouves, aquilo que eu digo.

Ouço, não ouço, aquilo que tu dizes.

Há até programas

em que todos ouvimos (ou não)

aquilo que dizemos.

E está certo, mas não avançamos.

Ou se avançamos é porque nos ouvimos um só.

Mas, pergunto eu:

é isto avançar,

se tu não ouves

aquilo que eu digo,

e se eu não ouço

aquilo que tu dizes?

O avanço vem com a palavra dada, não emprestada.

Com a que é oferecida e recebida.

Palavra só minha e tua, só tua e minha

Como o nosso fato, o teu, o meu fato.

Os teus olhos verdes e os meus castanhos.

Olhos, só olhos, mas verdes, castanhos.

\footnotetext{
${ }^{4}$ CINATTI, 2000, p. 81. Na síntese de Merleau-Ponty, "não existe homem interior, o homem está no mundo, é no mundo que ele se conhece” (MERLEAU-PONTY, 1945, p. v). 5 "Et erunt duo in carne una" (Gênesis 2, 24).
} 
A tua amizade, a minha paixão.

Vamos pois dançar um vira tamanho

que eu me canse logo e tu logo não.

E me dês o braço e eu a ti a vida

que pulsa no braço que me ajuda a mim.

E se acaso o vira nos cansar de vez,

a ti que tens alma, a mim que tenho corpo.

$\mathrm{E}$ a voz emudecer por não ser recebida.

Caiamos de borco, caiamos de borco

e demos as mãos,

as mãos,

as mãos.

E o vira será a dança mais linda!

\section{Envio}

O resto é conversa, não é caridade.

Egoísmo vão e pouca verdade

fincada no chão.

Não entra na roda,

nem joga ao pião.

E quanto a esse amor-

Oh quanta fartura!

Oh quanta ilusão! ${ }^{6}$

O frente a frente torna-se, neste caso, num literal face a face, imagem de toda a relação ética, pois, como sublinhou Lévinas, o encontro do rosto de outrem representa o encontro com a sua nudez mais elementar, com a sua mais exposta vulnerabilidade. É assim que a relação amorosa se torna, ela mesma, a mais motivada metáfora da própria intersubjectividade, já que esta se funda, por essência, na intercorporeidade, com a particularidade de anular toda a relação social e toda a relação de poder, tornando impertinente a relação entre mestre e escravo, como também assinalou com insistência Lévinas. ${ }^{7}$

Mas qual a importância desta troca de olhares, implicada no face a face, que o poeta permanentemente experiencia, de modo a erigi-la como eixo estruturador dos seus versos? As suas implicações medem-se em duas consequências distintas, mas complementares. Em primeiro lugar, a reversibilidade da visão imposta pelo face a face relativiza a posição de poder que o sujeito detém sobre as coisas, até no plano etnocêntrico

\footnotetext{
${ }^{6}$ CINATTI, 1992, p. 210-211.

${ }^{7}$ Ver LÉVINAS, 1996, p. 80-82.
} 
mais alargado, pois, neste caso, o seu papel é simultaneamente, num ritmo alternado, o de sujeito e o de objecto de um outro sujeito, como se verifica na complexa rede de olhares tecida neste "Encontro", de Lembranças para S. Tomé e Príncipe (1979):

\author{
De frente, a face, \\ olhos de luz, \\ claros de água límpida, \\ riso na face que me identifica \\ lucidamente a face dos negros \\ que se entreolham \\ como se deles fossem \\ os olhos que os fitam. ${ }^{8}$
}

Em segundo lugar, a partir do momento em que o sujeito partilha a sua visão, é a própria visão do mundo que é partilhada ou descentrada, o que implica necessariamente que o mundo que esse sujeito dá a ver seja o mundo de cuja visão ele é, não sujeito, mas co-sujeito. Nos termos de Merleau-Ponty, o mundo é a co-visão do mundo, e a intropatia faz-se telepatia, como nestes versos de 56 Poemas (1981):

Não dos mortos a coroa dos mártires, o epitáfio em mármore esculpido, mas dos vivos que, ressuscitados, foram de novo mortalmente feridos.

Desses eu canto a beleza extrema, a noite elástica de tantos relâmpagos caindo a fundo, como num crepúsculo de faces pálidas, corpos moribundos. $\mathrm{O}$ que procuro, o que neles descubro é a visão do mundo a que assistiram no espaçotempo de entre ir e vir e o regresso ao desconhecido. $\mathrm{O}$ que procuro - algumas palavras que me revelem o prodigioso mistério aberto entre duas almas, antes que seja tarde e a noite avance, a morte vença de uma vez para sempre e deles não fique senão o vislumbre. ${ }^{9}$

${ }^{8}$ CINATTI, 1992, p. 365.

${ }^{9}$ CINATTI, 1992, p. 650. 
"O que procuro, o que neles descubro / é a visão do mundo a que assistiram": neste regime, o mundo é, rigorosamente, intermundo, um mundo colectivo e objectivo constituído a partir de uma intersecção de olhares, porquanto, na lição de Husserl, "o mundo intersubjectivo é o correlato da experiência intersubjectiva, quer dizer, mediatizada pela 'intropatia", e, na de Merleau-Ponty, o intermundo é o mundo onde "se cruzam os nossos olhares e se recortam as nossas percepções". ${ }^{10}$

Significa isto, em termos muito simples, que a evidência pode ser também, e é, um modo de aparição colectiva do mundo, como de resto assinalou o próprio Husserl na sua Krisis, já em 1936: porque eu partilho o mundo com outros, os outros assinalam-me aspectos do mundo que eu não vi, levam-me a rectificar a minha percepção, e assim contínua e reciprocamente. O mundo é, pois, "qualquer coisa que é possível experimentar de forma concordante", quer dizer, em séries de experiências confirmando-se umas às outras, e o que aparece em experiências concordantes é justamente o "existente" em regime de "horizonte universal". ${ }^{11}$ Ser real significa, em última análise, ser objecto de uma síntese continuamente concordante de intuições, e o mundo, enquanto horizonte dessas coisas reais, está ele próprio em constante processo de validação e de correcção. Correlativo à comunidade dos homens, o mundo funda então a sua objectividade no facto de aparecer a vários sujeitos, de ser incessantemente reconhecido e validado por eles, como na súmula de Os Poemas do Itinerário Angolano (1974):

[...]
Junto ao corpo de Angola
cabeça, o que mais demora,
e vou-me, sem ter-me, agora,
no que bebi nas pupilas
de tantos que me fixaram.
Olhos foram passarinhos
ressurgindo a olhos vários.
Olhos sobreaquecidos
pelo suor de muitos homens. ${ }^{12}$

${ }^{10}$ HUSSERL, 1950, p. 509; MERLEAU-PONTY, 1945, p. 73.

${ }^{11}$ HUSSERL, 1976, p. 185 e subsequentes. Husserl acentua que o mundo é mundo para a comunidade humana desde o nível simples da percepção, pois esta é já, em todo o caso, "comunitária". Como assinalaram Kelkel e Schérer, "a possibilidade de um mundo objectivo fundar-se-á sobre a existência efectiva de uma comunidade intersubjectiva" (1982, p. 49). ${ }^{12}$ CINATTI, 1992, p. 430. 
Trate-se do choque dos olhares que a relação amorosa, melhor do que qualquer outra, põe em cena, ou da sua intersecção, fundando a possível objectividade da visão do mundo, o certo é que este face a face representa o fundamento sensível, porque visual e visível, da ética pressuposta numa poética do testemunho que Ruy Cinatti cultivou, com alguns dos seus coetâneos e com base na formulação teórica de Jorge de Sena. Na ética subjacente a essa poética, o valor essencial da responsabilidade só pode ser respeitado mediante uma atitude por definição intersubjectiva, a fidelidade: "é a minha responsabilidade em face de um rosto que me olha como absolutamente estranho [...] que constitui o facto original da fraternidade", sustenta Lévinas em Totalidade e Infinito. ${ }^{13}$

Ver o Outro enquanto ele me vê e ver o mundo com o Outro constituem dois actos perceptivos que, para lá da intencionalidade obrigatória que encerram, trazem consigo um pressuposto ético iniludível: a partilha do olhar e da visão implica a fidelidade ao Outro que eu vejo e a fidelidade ao que ele vê comigo, e esta fidelidade só pode ser observada a partir de uma posição de responsabilidade perante esse Outro e o mundo que com ele vejo, o que equivale a dizer, perante mim mesmo enquanto sujeito histórico.

Face à visão do Outro, por conseguinte, a fidelidade e a responsabilidade são não só obrigatórias como fáceis, uma vez que não põem em causa a integridade do $\mathrm{Eu}$, acentuando até a sua individualidade no seio da multidão, como defenderam Sartre e Lévinas na linha do Dostoiévski de Os irmãos Karamazov, ao proclamar que nós somos todos responsáveis por tudo e por todos perante nós, e eu mais do que todos os outros..$^{14} \mathrm{O}$ olhar é responsável, e as imagens, mesmo as poéticas, não podem ser senão éticas. Portanto, para Ruy Cinatti, um dos "sobreviventes responsáveis", para usarmos a expressão de Lévinas, da segunda metade do século XX, ser responsável é ver o Outro e responder-lhe. Neste sentido, a poesia só pode ser, como de facto acontece, conversa no seu sentido mais originário, cor ad cor loquitur, intersecção de vozes ou troca ética.

\footnotetext{
${ }^{13}$ LÉVINAS, 1988, p. 191.

${ }^{14}$ Sartre revisita o lema de Dostoiévski em 1946, no breve ensaio La Responsabilité de l'Écrivain: "Dostoievski disse: 'Todo o homem é responsável por tudo perante todos'. Esta fórmula torna-se todos os dias mais verdadeira. À medida que a colectividade nacional se integra na colectividade humana, à medida que cada indivíduo se integra na comunidade nacional, podemos dizer que cada um de nós se torna cada vez mais responsável" (SARTRE, 1998, p. 7).
} 
Eis-nos de volta ao princípio: a "santa realidade" dada a ver por um homem em situação equivale, na obra de Cinatti, à realidade dada a ver por um poeta em relação, e esta sua condição humana e poética resulta tão só de este poeta ver com e ser visto por. A base desta pulsão situou-se no foco da experiência, conceito que virá a adquirir importância crescente no discurso metapoético de Ruy Cinatti. Numa das duas "Cartas a um vanguardista sobre a arte e a vocação literária", divulgadas em 1939, o escritor já defendia que um estudante que muito decore, por exemplo, "nada sabe em comparação com o camponês conhecedor dos campos destinados à semeadura ou à plantação". ${ }^{15}$ Desde cedo, a experiência representa verdadeiramente o vivido, Erlebnis, onde se aliam inextricavelmente o sujeito que vê e o sujeito que toca o que vê, quer dizer, o sujeito contemplativo e o sujeito activo. Por isso, não admira que, numa das composições em que mais intencionalmente reflecte sobre a arte poética, Cinatti tenha remetido a génese da sua criação para a passagem dos Cadernos de Malte Laurids Brigge, de Rilke, que tantos poetas da sua geração - de Jorge de Sena a Sophia de Mello Breyner, passando por Eugénio de Andrade - tomaram como lema:

\section{$[\ldots]$}

Pouco a pouco lá vem o encantamento

Para refrescar a alma entristecida

Para se ser poeta...

O resto... Mas leiam a página 26 da edição francesa

Do Rilke - Malte Laurids... O resto

É um trabalho a dois até que a alma fique pura

E a carne nua,

Em cada momento a carne pura e a alma nua.

Assim será a vida uma lenta agonia

Com a visão do paraíso sempre a dois passos. ${ }^{16}$

O excerto da página 26 da edição francesa lida por Cinatti é, naturalmente, o mais conhecido da obra de Rilke, onde Malte regista:

Creio que devia começar a trabalhar, agora que aprendo a ver. [...] Ah, mas que significam os versos, quando os escrevemos cedo! Devia-se esperar e acumular sentido e doçura durante

${ }^{15}$ CINATTI, 1939, p. 4.

${ }^{16}$ CINATTI apud STILWELL, 1995, p. 57. 
toda a vida e se possível uma longa vida, e então, só no fim, talvez se pudessem escrever dez versos que fossem bons. Porque os versos não são, como as gentes pensam, sentimentos (esses têm-se cedo bastante) - são experiências. Por amor de um verso têm que se ver muitas cidades, homens e coisas, têm que se conhecer os animais, tem que se sentir como as aves voam e que se saber o gesto com que as flores se abrem pela manhã. [...] E também não é ainda bastante ter recordações. É preciso saber esquecê-las quando são muitas, e é preciso ter a grande paciência de esperar que elas regressem. Pois que as recordações mesmas ainda não são o que é preciso. Só quando elas se fazem sangue em nós, olhar e gesto, quando já não têm nome e já não se distinguem de nós mesmos, só então é que pode acontecer que, numa hora muito rara, do meio delas se erga a primeira palavra de um verso e saia delas. ${ }^{17}$

Longe do angelismo das Elegias de Duíno que viria a deixar marcas em Sophia de Mello Breyner Andresen ou em Eugénio de Andrade, longe ainda da tradição dos "rilkinhos" que, com a sua inconfundível ironia cáustica, Jorge de Sena viria a denunciar num ensaio de 1953, e longe até do repúdio impiedoso da "sentimentalidade imediata" manifestado na passagem a que alude, o que em Rainer Maria Rilke interessou a Ruy Cinatti foi sobretudo - como a Sena, que lera a mesma edição francesa da obra - o entendimento da actividade criadora como "ansiosa escuta do mundo", realizada pela "consciência poética" regida por uma especial "expectativa exigente". No entender de Cinatti, portanto, e desde muito cedo, a poesia só podia fundar-se na experiência, com a dupla implicação espáciotemporal que esse princípio necessariamente exigia: i) a experiência só tem lugar no mundo; ii) não existe experiência que não seja temporal. Ou seja, para Ruy Cinatti, a experiência enquanto fonte da criação poética é, essencialmente, o único ponto onde a Poesia e a História se podem encontrar.

Esta experiência fundada na presença obedeceu, no decurso do tempo e da obra, a três andamentos específicos, rumo a uma circunstancialidade cada vez mais acentuada e explícita: de um sujeito

${ }^{17}$ RILKE, 1974, p. 41-42. A primeira edição desta tradução, da responsabilidade de Paulo Quintela, só veio a lume em 1955, razão pela qual a geração de Cinatti travou conhecimento com a obra através da tradução francesa. 
lírico cuja historicidade ainda difusa se expôs em versos marcados pela angústia, a poesia de Cinatti alargou o seu círculo ético graças à poética do testemunho que o irmanou, nas décadas de 1940 e 1950, aos poetas dos Cadernos de Poesia com quem partilhou esse projecto editorial, e muito em especial a Jorge de Sena, para culminar numa poética da denúncia de cariz altamente militante, onde as expressões de raiz indicial "apontar o dedo" ou "indigitar" exibem toda a pregnância do seu sentido literal.

É preciso lembrar que, na sua dupla condição humana e poética, Ruy Cinatti viveu algumas das convulsões históricas e sociais mais agudas do século XX, à escala mundial e nacional. Cresceu sob o impacto do primeiro grande conflito internacional (1914/1918), no seio do qual nascera (1915); a juventude - ou seja, os primeiros anos de escrita - foi marcada pela sangrenta Guerra Civil de Espanha (1936/1939), seguida de imediato pela Segunda Guerra Mundial (1939/1945), atravessada pelo Holocausto, com o estridor colossal de Hiroshima e Nagasaki (1945). No momento em que, na história do mundo, as cinzas arrefeciam graças à instauração da Guerra Fria (1947), seria a história do País a agredir o seu espírito sempre sobressaltado, obrigando-o a presenciar o destino infeliz dos seus territórios ultramarinos de estimação, entre a guerra colonial (1961/1974), o abandono e a dolorosa entrega de Timor à ocupação pela Indonésia (1975). Tudo isto culminando no 25 de abril de 1974, cuja posteridade sinuosa viria a ser o derradeiro motivo do seu desencanto. A sucessão vertiginosa de acontecimentos históricos desta amplitude deixou marcas indeléveis no andamento da obra, quer no plano meramente poético, quer no da reflexão poetológica explícita, que viria também a acentuar-se no decurso do tempo.

A face agónica da angústia de Cinatti exprime provavelmente a reacção mais adequada ao mundo em que se formou, um mundo de luta, de dor e de morte. Basta pensar que os seus dois primeiros livros, Nós não Somos deste Mundo, de 1941, e Anoitecendo, a Vida Recomeça, de 1942, viram a luz do dia em pleno conflito mundial, e no rescaldo da Guerra Civil de Espanha, integrando-o assim naquela geração singular de poetas que, nascidos nos anos da eclosão da Primeira Grande Guerra e nos que imediatamente se seguiram, não tiveram qualquer experiência real de uma Europa pré-guerra, tendo vivido os anos de formação pessoal e social "vagueando entre dois mundos, / Um morto, o outro impotente para nascer", para utilizarmos os versos de Matthew Arnold que Tomaz Kim, companheiro de geração e de projectos, tanto gostava de citar. O mesmo Tomaz Kim, de resto, um dos coetâneos de Cinatti que com mais 
veemência impuseram uma obra como voz do seu tempo, resumiria bem a identidade dessa paisagem geracional, ao citar o D. H. Lawrence de Kangaroo na abertura do prefácio aos Ensaios de Doutrina Crítica de T. S. Eliot, para advertir: "Foi em 1915 que findou o velho mundo". Kim comenta a frase de Lawrence, constatando que "a primeira Grande Guerra mundial assinala de forma bem vincada o início da modernidade para o qual tanto contou a colaboração dos que sobreviveram à hecatombe, muitos deles, por paradoxal que pareça, parte daquela multidão de 'Hollow Men' a que T. S. Eliot se refere no poema do mesmo nome". ${ }^{18}$

Se outra afinidade não tivessem os poetas que, ao lado de Ruy Cinatti e de Tomaz Kim, consumaram o projecto dos Cadernos de Poesia, aparecidos no dealbar da década de $1940,{ }^{19}$ teriam pelo menos em comum o sentido histórico de terem nascido biologicamente com a Primeira Grande Guerra, e poeticamente com a Segunda, o que desde logo explica o espírito de sobressalto e angústia que distinguiu a disposição ética e existencial de toda a sua geração. No que respeita especificamente aos Cadernos, essa disposição ficaria logo exposta no primeiro fascículo da revista, pela pena do próprio Tomaz Kim, na sequência "Poemas sem título": "Agora que o sangue derramado / nos embala e nos ensina a odiar... / Agora que o pavor e a morte / enchem o espaço... / Agora que a metralha / extingue as canções dos poetas...". ${ }^{20}$ Onze anos volvidos, já na abertura da segunda série, o papel decisivo que a Guerra havia desempenhado na formação das personalidades poéticas e na mundividência desolada dos escritores de então ficava clara em "Europa a ferros" e "Arquipélago", também de Kim, ou na "Metamorfose" do próprio Ruy Cinatti, datada do último ano da Guerra:

${ }^{18}$ MONTEIRO-GRILLO, 1997, p. 11.

${ }^{19}$ Os Cadernos de Poesia duraram catorze anos, distribuídos por três séries (1940/42, 1951 e 1952/53), e perfizeram um total de quinze fascículos. A par de Cinatti e Kim, a publicação teve como principais responsáveis Jorge de Sena e José Blanc de Portugal, a que viriam a ser associados Sophia de Mello Breyner Andresen e Eugénio de Andrade, muito em virtude da sua independência estética, e não por terem tido qualquer papel activo na consecução do projecto.

${ }^{20}$ CARLOS; FRIAS, 2004. Cadernos de Poesia, 1, Lisboa, 1940, p. 7. O primeiro livro de Kim, Em cada dia se morre..., anunciava já esta obsessão pelo atentado à dignidade humana que a guerra representava, bem figurado na temática sangrenta, na expressão metralhada e na síntese "Nocturno para a minha geração", onde proclamava: "As cordas e as canções / dos nossos violinos / são de fel e vinagre” (KIM, 1939, p. 15). 
Surdem do fio da terra dos homens,

Noites azuladas e ígneas.

Palavras no seio dos homens.

Exigência no seio dos puros,

Dos puros que semeiam

Sementes do inferno e do céu.

$[\ldots]$

Perdida voz, eu te procuro

Junto dos outros.

Oiro descoberto, eu te procuro

Na solidão imensa que nos cerca. ${ }^{21}$

Tzara disse-o com inteira razão: a poesia estava enterrada na história até ao pescoço, pois

ela não seria aquilo que é, aquilo que não é, se a guerra de Espanha não a tivesse atravessado como uma faca, se Munique não a tivesse feito corar com esse encarnado que é a cor mais exaltante que ainda conhecemos neste mundo, se Vichy não fosse a vergonha onde a própria dor ficara sulcada pelo sangue de tantos inocentes, e se os nazis não lhe tivessem dado esse sopro que suscitou o vento de revolta insurrecional, cujo alcance e glória ainda somos muito jovens para medir. ${ }^{22}$

Ruy Cinatti foi, com os seus coetâneos, testemunha ocular de uma época trágica em que, na apreciação de Merleau-Ponty, o herói deixou de ser Lúcifer ou Prometeu, e passou a ser o próprio Homem: não um céptico, não um diletante, não um decadente, mas o Homem com "a experiência do acaso, da desordem e do fracasso, de 36, da Guerra de Espanha, de Junho de $40 " .{ }^{23}$ Isto é, o homem no mundo ou deste mundo, marcado pela mais pura "consciência infeliz desta condição infeliz". Como bradariam os versos crus de Vítor Matos e Sá anos depois, tratava-se agora do homem experimentando "a violenta companhia / insubstituível do mundo". Antes de tudo o mais, urgia dar a ver este mundo e a sua desumanidade, o que,

${ }^{21}$ Cadernos de Poesia, 6, Lisboa, 1951, p. 2122. Reproduzido em CINATTI, 1992, p. 111. O livro do nómada meu amigo.

${ }^{22}$ TZARA, 1966, p. 7-8.

${ }^{23}$ MERLEAU-PONTY, 1963, p. 330-331. 
no caso de Cinatti e dos seus companheiros, rapidamente conduziu a uma atitude existencial e poética de revolta e responsabilidade, bem condensada na revisão de Descartes por Camus em 1951: "Revoltome, logo somos". Ora, Cinatti sabia que a responsabilidade do poeta reside na condição humana da obra, que é a sua pertença ao mundo. $\mathrm{E}$, portanto, enquanto poeta do pós-guerra, mais não lhe restou do que exprimir responsavelmente esse sentimento do mundo a que aludia Carlos Drummond de Andrade em 1940, porque agora o poeta, como o homem de Sartre, carrega o peso do mundo nos seus ombros, mesmo quando no poema o mundo não pesa "mais que a mão de uma criança".

Percebe-se assim com facilidade que o canto da agonia desta waste land, infindável quarta-feira de cinzas vivida por uma multidão de homens vazios, tenha sido a causa mais imediata da atitude de conjunto que, tal como se explicitou no texto introdutório da terceira série dos Cadernos de Poesia, em 1952, era a única passível de homogeneizar o grupo, a vários títulos heterogéneo, sobre o mesmo fundo comum:

A atitude fundamental dos 'Cadernos', que inspirou a sua série antológica, como a não antológica 2. ${ }^{\text {a }}$ série, é uma atitude que releva da ordem ética, e tão inseparável da consciência de dignidade humana, que não admira seja de difícil compreensão para literatos e outros géneros afins. ${ }^{24}$

Corpo e alma de Jorge de Sena, a segunda e a terceira séries dos Cadernos traziam consigo a marca do entendimento testemunhal da expressão poética veiculado pelo autor de Sinais de Fogo, que assim dava profundidade teórica à vocação de responsabilidade perante $o$ mundo que todos os poetas dos Cadernos se arrogavam, e que, no seu caso particular, era objecto de verdadeira perseguição. "Sempre à minha frente se levanta o problema da responsabilidade", confessava a Cinatti já em 1942, alertando-o para a urgência de "nunca deixar as palavras nas mãos daqueles que não têm tão aguda noção da responsabilidade". ${ }^{25}$ Estas palavras responsáveis converter-se-iam, quase vinte anos mais tarde, na própria definição da arte poética enquanto arte do testemunho, isto é, enquanto "ciência, melhor ou pior informada, racional ou intuitivamente

24 “A poesia é só uma 1940/1951/1952”. Cadernos de Poesia, 13. Lisboa: 1952, p. 3-4. Reproduzido em CARLOS, FRIAS, 2004.

${ }^{25}$ SENA, 1984, p. 68-69. 
obtida, de exprimirmo-nos responsavelmente", tal como Sena a exporia no importante prefácio ao volume Poesia $I .{ }^{26}$ Outra coisa não afirmavam os versos dedicados ao próprio Cinatti, e compostos em 1952 para serem publicados em Peregrinatio ad Loca Infecta, onde Sena sintetizara a sua visão da arte poética como esta ciência de se exprimir responsavelmente:

Os anos passam; mas, desta passagem, a permanente essência em nós se cumpre, que para testemunho só nascemos.

Mas de que falas tu? De ti? Do mundo?

Ou do intervalo em que te aceitas outro, precisamente quando mais te julgam tu? ${ }^{27}$

Directamente dirigidos a Ruy Cinatti, e retomados pelo poeta como epígrafe de 56 Poemas, o que estes versos colocam em causa é o estabelecimento desse regime de coresponsabilidade a determinar a relação do poeta e da poesia com o tempo e a história, que Sena desenvolveu no prefácio de 1961, onde tal coresponsabilidade se apresenta como a "única garantia de uma autenticidade", e permanente apelo "para a comunhão de todos os inquietos, todos os insatisfeitos, todos os que exigem do mundo, para os outros, a generosidade que lhes foi negada". Assim, os textos de abertura das segunda e terceira séries dos Cadernos, ambos escritos por Sena, recuperam e acentuam explicitamente a divisa ética implícita no projecto da primeira série, numa definição da poesia que a exibe como compromisso entre o poeta e o mundo. Tutelado pela citação de Gomes Leal que abre o número 6 - "os poetas já hoje não são uns simples fazedores de madrigais, são uns directores do espírito dos povos" -, o texto introdutório do primeiro fascículo da segunda série apresenta a expressão poética como resultado de "um compromisso firmado entre um ser humano e o seu tempo, entre uma personalidade e uma consciência sensivel do mundo, que mutuamente se definem”, para acentuar que "tudo o que não atinge este nível não é poesia".

Tomaz Kim, qualificado com frequência como um quase precursor do neorealismo, ${ }^{28}$ criticava ao imagismo anglo-americano ter-se mantido

\footnotetext{
${ }^{26}$ SENA, 1988, p. 24.

${ }^{27}$ SENA, 1989, p. 27. O poema data de 3 de março de 1952.

${ }^{28}$ Em 1960, Ruy Cinatti confidencia a Arnaldo Saraiva que a ideia de formação dos Cadernos de Poesia por parte de Tomaz Kim se devera mesmo, em parte, "ao namoro
} 
"divorciado dos problemas decisivos da sua época", o que decorria, segundo ele, de o movimento ser "demasiado estático e limitado para poder absorver o pulsar dos novos tempos". ${ }^{29}$ Por seu lado, José Blanc de Portugal defendia, ainda nas páginas dos Cadernos, que "toda a grande poesia é informada e informadora". E até os dois poetas que mais visivelmente praticaram aquilo que poderia ser descrito como uma poesia pura tiveram sempre no seu horizonte esta natureza vigilante e atenta do acto poético, conforme se pode depreender de algumas reflexões posteriores: num dos metatextos incluídos em Rosto Precário, Eugénio de Andrade viria a dizer claramente que desde muito cedo escrever fora, para si, "a ambição de exprimir uma certa consciência do mundo, consciência infeliz, naturalmente, mas responsável", citando Antonio Machado para relembrar que a poesia é "palavra no tempo", e concluir que a palavra do poeta, "temporal, por excelência", "é uma palavra preocupada"; 30 e Sophia, pretendendo também rodear o mundo do seu "maternal cuidado", diria da poesia que "estabelece a relação inteira do homem consigo próprio, com os outros, e com a vida, com o mundo e com as coisas", do poema que "fala não de uma vida ideal mas sim de uma vida concreta", e do poeta que, ao ver "o espantoso esplendor do mundo é logicamente levado a ver o espantoso sofrimento do mundo". "E é por isso que a poesia é uma moral", conclui a escritora de Coral, não perdendo nunca de vista a natureza da condição poética segundo a qual, como lembrava René Ménard em 1959, "a Poesia pode ser a beleza da Moral". ${ }^{31}$

E, de facto, foi este responsável sentimento estético do mundo que se sobrepôs à inegável diversidade dos vários autores dos Cadernos, fonte de obras tão radicalmente distintas como as de Sophia de Mello Breyner e de Tomaz Kim, ou as de Jorge de Sena e de Eugénio de Andrade, perdurando como o vívido pano de fundo sobre o qual toda a geração se moveu, conforme esclareceu Eduíno de Jesus, num texto de grande clarividência:

[...] se, como propósito e facto de isenção literária, os

Cadernos de Poesia foram, num período de partidarismo

mal correspondido" do Novo Cancioneiro, e ao "desejo de evitar os defeitos e superar as qualidades patenteadas naquele movimento" (SARAIVA, 1960, p. 551).

${ }^{29}$ MONTEIRO-GRILLO, 1951, p. 18.

${ }^{30}$ ANDRADE, 1979, p. 45.

${ }^{31}$ ANDRESEN, 1999, p. 7; MÉNARD, 1959, p. 21. 
literário [...], de eficacíssima oportunidade, do seu saudável ecletismo não teriam passado à história, por outro lado, mais do que os certos valores individuais aí congregados (não, portanto, os Cadernos de Poesia como poesia de um grupo que, na realidade, pretendeu sempre nunca existir...), se, por acaso, determinadas afinidades estéticas não aproximassem os organizadores desses fascículos, como se de um grupo fizessem parte. [...] aceitemos $[\ldots]$ que uma publicação de coisas de poesia (versos e ensaios sobre) que, bem ou mal a seu grado, impõe uma poesia e um conceito dela peculiares, constitui um movimento poético. Assim, e partindo do princípio de que há uma poesia dentro dos Cadernos que pode ser chamada a poesia dos Cadernos de Poesia, temos que houve (e talvez possamos dizer que há, apesar da dispersão porventura não definitiva dos seus poetas fundamentais) um movimento poético a partir daquela publicação. Decerto, encontramos no fascículo 6 (o primeiro da II série), a declaração expressa de que os Cadernos de Poesia nunca representaram um grupo literário, nem sequer uma associação de poetas. Mas veja-se que o acaso (?) reuniu, para a fazerem, os poetas Jorge de Sena, José Blanc de Portugal, Ruy Cinatti e Tomaz Kim, os poetas mais caracteristicamente dos Cadernos de Poesia. Quer dizer, portanto, que, ao professarem a sua posição antigrupo, os poetas mais representativos dos Cadernos de Poesia [...] assumiam, em grupo, uma atitude ante a Poesia. Ora é assim que se forma um grupo literário: definindo uma comum atitude. ${ }^{32}$

Mas qual o papel de cada um destes poetas e das suas obras no entendimento testemunhal da vocação poética, preconizado pelos organizadores dos Cadernos, que envolvia uma dupla fidelidade ao mundo e à poesia, quer dizer, um compromisso entre o poeta e o seu tempo que fosse capaz de superar a contingência desse mesmo tempo, firmando-se numa invulgar dialéctica fundada no conceito de relação, tal como expunha o texto introdutório do fascículo 6, assinado por Cinatti e Sena, José Blanc, Tomás Kim e José Augusto França? Atentemos no núcleo do manifesto:

32 JESUS, 1960, p. 546-547. 
Se a expressão poética é (ou resulta de) um compromisso - e sublinhe-se de uma vez para sempre que esse compromisso se não destina a captar o "inexprimível"...-, evidente se torna que a poesia só existe como relação: a relação que relata e a relação que relaciona entre si duas entidades. Portanto, quem se subordina à Poesia (com maiúscula) na intenção de esquivar-se a outras subordinações (a Deus, ao Mundo, ao próprio Homem), trai-se a si próprio, à consciência sensível que do mundo poderia ter, e à Poesia - a relação - que mais do que tudo julga ambicionar. E igualmente se trai a si próprio, à sua consciência sensível do mundo, e à relação que pretende criar, quem subordine esta última não àquilo que pensa e sente, mas ao que entende dever ser tal relação, tal expressão poética, tal poesia. ${ }^{33}$

Desde o primeiro livro de poesia de Cinatti, editado no segundo ano de vida dos Cadernos, a máxima "nós não somos deste mundo, mas é no mundo que eu vivo" ditou um percurso de alta fidelidade ao mundo e ao Outro - ao intermundo e ao entremundo - que converteu a matricial consciência infeliz do poeta numa consciência sensível e vigilante, isto é, numa consciência porosa e permeável, lugar de convergência das imagens projectadas pela retina, e já calibradas pela intencionalidade de um olhar responsável. De acordo com a leitura de João Rui de Sousa, é mesmo “à luz desse enlace ["nós não somos deste mundo, mas é no mundo que eu vivo"], dessa consciência duma fundamental dualidade a que não pode furtar-se, que Cinatti explicita todo um longo curso testemunhante do tal mundo em que vive". ${ }^{34}$ Esse olhar responsável não foi senão a expressão mais exacta da natureza essencialmente relacional da poesia, no duplo sentido que Sena lhe dera, ao redigir o texto programático de abertura da segunda série dos Cadernos. Em obediência a um princípio de fidelidade e de responsabilidade, a consciência sensível tornouse consciência vigilante, no exacto sentido em que, como frisou Husserl, "a vigilância é a própria vida da consciência, mas tomada no mundo", o que faz com que vigilância e actualidade sejam sinónimos. A consciência vigilante é, pois, a consciência que vê a actualidade, ou, por outras palavras, a consciência que assiste ao que se passa no mundo porque é uma consciência presente,

33 “A poesia é só uma 1940/1951". Cadernos de Poesia, 6, p. 5. Reproduzido em CARLOS, FRIAS, 2004.

${ }^{34}$ SOUSA, 1992, p. 18. 
no duplo sentido em que tem presença e se situa no presente: "Cada passo da História me é presente. / Sou o compasso do mundo", anunciava já Cinatti em "O fenómeno humano" de O livro do nómada meu amigo. ${ }^{35}$ $\mathrm{E}$, anos mais tarde, em Conversa de rotina, escreve:

\author{
A poesia, \\ igual ao tempo, \\ há de servir para muita história \\ trágica e não marítima \\ como a de outrora. \\ Há de servir \\ porque o devir a quer \\ maravilhada ao amanhecer. \\ O que era já não sou, não posso querer \\ nem o passado perdoa. \\ O que me prende \\ é o presente, futuro \\ magro, mas fecundo. ${ }^{36}$
}

${ }^{35}$ CINATTI, 1992, p. 110. O título do poema recupera o da obra central de Teilhard de Chardin, Le Phénomène Humain, com primeira edição em 1955.

${ }^{36}$ CINATTI, 1992, p. 407. Observe-se a semelhança destes versos com uma das mais famosas e programáticas artes poéticas de Carlos Drummond de Andrade, em Sentimento do Mundo (1940), os versos finais do poema "Mãos dadas": "O tempo é a minha matéria, o tempo presente, os homens presentes, / a vida presente". Aproximação que tem algum sentido se pensarmos que o mesmo Drummond de Sentimento do Mundo aparece num dos poemas de Lembranças para S. Tomé e Príncipe, onde Cinatti invoca "os inocentes de Drummond de Andrade", referindo-se decerto ao texto "Inocentes do Leblon" desse mesmo volume (ver CINATTI, 1992, p. 368). Drummond encontra-se ainda no título do poema "Lição de coisas", em Borda d'Alma, inspirado no volume homónimo do poeta brasileiro, ou em "Poema do 25 de Abril", que repete paródica e explicitamente o já paródico texto de Drummond "Bahia", do inaugural Alguma Poesia: "É preciso fazer um poema sobre a Bahia... / Mas eu nunca fui lá". O "Poema do 25 de Abril”, dedicado a Joaquim Namorado, resume-se ao verso “- Não estava lá!”, e informa que se trata de "Alusão ao poema de J. N., que sob o título de "Poema dos Mares do Sul', se reduziu a 'Eu não fui lá', por manifesta influência do 'Poema do Bêco' de Manuel Bandeira ou de um outro de Carlos Drummond de Andrade" ( $O$ a Fazer, Faz-se. CINATTI, 1992, p. 569). De acordo com o testemunho do próprio Cinatti, os escritores brasileiros cedo fizeram parte do seu leque de leituras: "Lia os modernos, pela mão de amigos mais velhos. Pessoa, Régio, os brasileiros, Eliot. Pela mão destes fui recuando no tempo, penetrando nos clássicos" (apud STILWELL, 1995, p. 419). 
A consciência vigilante é, portanto, para Cinatti, o próprio fundamento do testemunho, quer porque o testemunho é, como sugeriu Fernando Guimarães nos termos de Sena, uma disponibilidade também vigilante, quer porque a presença, condição sine qua non da vigilância, é, como fez notar Jorge Fazenda Lourenço, "o fundamento ético da demanda", e, por conseguinte, "uma forma de testemunho". ${ }^{37}$ É caso então para dizer, com inteira propriedade, que, na óptica de Ruy Cinatti, toda a imagem estética tem a sua ética, como de resto é próprio da condição da testemunha ocular. Num rentável cruzamento, a poesia é testemunho, e o poeta é testemunha, como virá a afirmar no pórtico de $O$ a Fazer, Faz-se, em 1976 - "RUY CINATTI / Testemunha atenta, veneradora e obrigada" -, para repetir, dentro do próprio livro, sobrepondo a intenção e a atenção:

\section{Sou testemunho \\ de um país de todos. \\ Atento estou! ${ }^{38}$}

Como se pode aferir, de acordo com um princípio existencialista bem sartriano, toda a angústia de Cinatti se pode explicar a partir de uma responsabilidade directa face aos outros homens que ela compromete. Em 1950, no texto Explorações Botânicas em Timor, diz mesmo:

[...] é doloroso verificar que não foi só a guerra que conduziu Timor ao estado em que se encontra. A culpa é nossa também. Cada um sente a parte de responsabilidade que, por herança, lhe cabe. Cada qual procura realizar então aquilo de que é capaz. Foi o que procurei fazer. ${ }^{39}$

E, numa carta inédita dada a conhecer por Peter Stilwell, insiste: "Nós somos todos responsáveis pelo que se está passando, mesmo quando a culpa nos não pertence". ${ }^{40} \mathrm{O}$ mesmo Jorge de Sena o diria com agudeza,

\footnotetext{
Em Aventura, Ruy Cinatti viria a divulgar a obra de Cecília Meireles, Ribeiro Couto, Álvaro Lins, Odylo Costa Filho e Cícero Dias (junte-se aos Cadernos e a Aventura o papel fulcral que a revista Litoral, editada em 1944/1945 e onde o próprio Cinatti também colaborou, desempenhou na divulgação da literatura brasileira, publicando autores como Graciliano Ramos, Ribeiro Couto e Sérgio Buarque de Holanda).

${ }^{37}$ Ver GUIMARÃES, 1996, p. 153 e LOURENÇO, 2000, p. 165.

${ }^{38}$ CINATTI, 1992, p. 565, 572.

${ }^{39}$ CINATTI, 1950, p. 42.

${ }^{40}$ CINATTI apud STILWELL, 1995, p. 298.
} 
na nota à "Dupla Glosa" acima citada: Cinatti foi "uma, além do mais, das raras - a não ser no povo - consciências altruisticamente sofredoras que há hoje em Portugal”. Em suma, ao invés da angústia que conduz ao quietismo, a angústia de Cinatti não foi, nos termos de Sartre, uma cortina que o separaria da acção, mas fez parte da própria acção. O que explica que, ao levar a cabo o projecto da revista Aventura, integralmente concebida e realizada por si, Cinatti tenha acabado por criticar "o acomodamento dos Cadernos de Poesia", em nome de uma atitude "militante", "dinâmica", em que a paz não excluísse a espada.

Mas a verdade é que, na abertura da segunda série dos Cadernos, o "acomodamento" que Cinatti sanciona era já sumariamente ultrapassado, devido à atitude imprimida à publicação pelo próprio Jorge de Sena, responsável então pela redacção do texto introdutório do número 6, onde, como já se mencionou, a vocação testemunhal da poesia era defendida em termos que não a dissociavam de uma finalidade de transformação do mundo, que Sena viria a explicitar no Prefácio a Poesia I, em termos muito claros: "à poesia, melhor que a qualquer outra forma de comunicação, cabe, mais que compreender o mundo, transformá-lo". A abertura da segunda série dos Cadernos anunciava também, em tom programático: "é preciso deixar que as mãos do homem e o olhar do poeta transformem o mundo à sua imagem e semelhança. O poeta não contempla - o poeta cria. Defende o que é atacado, e ataca o que é defendido". Se a primeira série dos Cadernos havia sido dominada por uma preocupação de carácter antológico que valera à publicação, na época, atributos como "eclética", o certo é que, nas séries seguintes, essa finalidade deu lugar a uma verdadeira "plataforma ética de entendimento", desenhando um percurso activo que seria reconstituído com toda a clareza ainda por Jorge de Sena:

Nos anos 40, [os Cadernos de Poesia] tentaram salvaguardar a qualidade da poesia (reconhecendo-a igualmente em "presencistas" e "neorealistas"), e, nos anos 50, quando nitidamente se desenhavam tendências esteticistas na poesia portuguesa, procuraram opor-lhe uma orientação comprometida com a realidade, sem prejuízo da qualidade intrínseca. ${ }^{41}$

${ }^{41}$ SENA, 1988, p. 205. Na síntese de Eduíno de Jesus, “a uma inicial posição meramente esteticista, preocupações ulteriores de ordem ética se teriam vindo juntando, ou melhor 
É por demais conhecida a atitude conciliadora que ditou o andamento das três séries dos Cadernos de Poesia: o postulado da "plataforma ética e não estética de entendimento", expresso no lema "A Poesia é só uma", ${ }^{42}$ explicaria que, num momento de alta conturbação histórica e estético-literária em Portugal, os fascículos dos Cadernos fizessem coabitar escritores de todas as épocas e de correntes contrárias, de diversos países e de orientações ideológicas e poetológicas radicalmente distintas, ${ }^{43}$ e que o grupo de poetas responsável pela revista aparecesse no seu tempo como uma espécie de "terceiro excluído".

Assim, foi mesmo o "homem inteiro", ou o poeta inteiro - que viria a atingir ainda especial expressão no "homem total" das folhas da Árvore, já no início da década de 1950 -, que repassou as páginas dos primeiros cinco fascículos dos Cadernos de Poesia, como as vindouras segunda e terceira séries, onde se descrevia o poeta como "um homem destinado a nele se definir a humanidade", a partir de uma estética de raiz ética que conciliava os quadrantes presencista e neorealista. Esta conciliação dialéctica obedecia, nos termos de Sena aplicados à sua própria obra, a um simultâneo desejo "de independência partidária da poesia social" e "de comprometimento humano da poesia pura", levada

dizendo: teriam vindo assomando à tona de uma consciência poética que, porventura, fora desde sempre empenhada eticamente, mas começara por colocar em primeiro lugar o poético na ordem das suas preocupações propriamente literárias" (JESUS, 1960, p. 550). ${ }^{42}$ A fórmula "A Poesia é só uma!" parece ter sido concebida por Cabral do Nascimento - "verdadeira cabeça sólida da I Série dos Cadernos", segundo o testemunho de Cinatti (apud STILWELL, 1995, p. 49. Carta a Mécia de Sena de 19 de Maio de 1981) -, que mantinha convívio frequente, no café Chave d'Ouro, com os poetas mais novos.

${ }^{43}$ São 57 os poetas que figuram nos cinco fascículos da primeira série dos Cadernos, que contemplam todo o leque das tendências poéticas afirmadas em Portugal desde o início do século XX: entre outros, Luiz de Montalvor, Cabral do Nascimento, João de Castro Osório, Carlos Queiroz, Adolfo Casais Monteiro, Tomaz Kim, José Blanc de Portugal, Sophia de Mello Breyner Andresen, Ruy Cinatti, Armando CôrtesRodrigues, António de Sousa, Alberto de Serpa, José Régio, Saúl Dias, João José Cochofel, Fernando Namora, Merícia de Lemos, Teles de Abreu [Jorge de Sena], Álvaro Feijó, Fernando Pessoa, António de Navarro, João Falco [Irene Lisboa], Natércia Freire, Afonso Duarte, José Gomes Ferreira, Francisco Bugalho, Fausto José, Vitorino Nemésio, Miguel Torga, Francisco José Tenreiro, Jorge de Sena, Afonso Lopes Vieira, Almada Negreiros, Edmundo de Bettencourt, António Ramos de Almeida, Mário Dionísio, Manuel da Fonseca, Sidónio Muralha, Pedro Homem de Melo e Eugénio de Andrade. 
a cabo mediante o entendimento testemunhal da expressão poética, vista como "fidelidade integral à responsabilidade de estarmos no mundo". Com efeito, a partir dos Cadernos de Poesia, este singular regime de coresponsabilidade entre o poeta e o tempo - ou, na síntese de Eduíno de Jesus, "este chamar da circunstância mundo tempo ao âmago da própria Poesia esteticamente considerada" - permitira articular dialecticamente a poesia social e a poesia pura em confronto no palco histórico-cultural da altura, sem ameaçar, nem a ligação ética do poeta ao mundo, nem a autonomia estética da poesia. Esta postura sustentava a articulação de presencismo e neorealismo, no início dos anos 1940, ou deste com o surrealismo, no decénio seguinte.

No tempo ainda dos Cadernos, a ética pautada pela acção embora não orientada para fins de propaganda política -, perseguida por Cinatti justificaria, entre outras coisas, que ele tivesse sido, a par de Sena e de Kim, um dos escritores da sua geração que mais assimilaram a poesia que então dominava o mundo anglófono. A poesia social dos anos 1930, produzida em torno da revista New Verse, e protagonizada pela figura tutelar de W. H. Auden, inspirara mesmo Tomaz Kim no projecto original dos Cadernos de Poesia, de acordo com o testemunho do próprio Cinatti. Publicada entre 1933 e 1939, "por causa de Auden” e sob a direcção de Geoffrey Grigson, New Verse afirmou-se praticamente como órgão oficial da poesia social inglesa, divulgando textos do próprio Auden, de Cecil Day Lewis, de Louis MacNeice, de Archibald MacLeish ou de Stephen Spender, fundamentais na formação cultural e literária de Ruy Cinatti, já então "cidadão britânico por nascimento na cidade de Londres". Cinatti pertence efectivamente a uma geração que desempenhou um papel determinante e inovador na divulgação da cultura e da literatura de língua inglesa, num país, como Portugal, que se encontrava então totalmente dominado pela cultura de origem francesa. Neste aspecto, foi muitíssimo significativa a actividade ensaística e de tradução, não só de Cinatti, mas ainda de Jorge de Sena, Tomaz Kim, José Blanc de Portugal e Cabral do Nascimento, que se dedicaram a traduzir, estudar e divulgar obras e autores fulcrais da literatura universal em geral, e da angloamericana em particular, de Malraux a Faulkner, de Shakespeare a Shelley, de Eliot a Chesterton, de Hopkins a Hemingway e D. H. Lawrence, passando pelos inevitáveis Auden e Spender. É a este importante trabalho que se refere Ruy Cinatti três décadas mais tarde, ao mencionar a "universalidade não programada" que os Cadernos de Poesia ostentavam desde a primeira 
hora, bem como Sena, ao concluir que a "dialéctica entre o que se tinha passado durante séculos de poesia em língua portuguesa e o que os outros países nos mostravam de modernidade nos salvou, em um dos períodos mais tristes da criação e da crítica literárias em Portugal, quando tudo se ensombrava em torno de nós". ${ }^{44}$ Assim se entende que a crítica tenha podido afirmar que "os poetas dos Cadernos, para além dos nossos, são também Hulme, Auden, Yeats, Eliot, Aldington". ${ }^{45}$

A um nível profundo, a poesia produzida em Inglaterra nos anos de crescimento cultural e literário destes poetas acabou por desempenhar um papel fundamental nos alicerces das suas próprias obras. Na verdade, as vozes de uma década "tão autoconsciente", nos termos de Robin Skelton, em especial as de Stephen Spender e de W. H. Auden - ou a do Dylan Thomas de "The hand that signed the paper fell a city" - respondiam, quer às necessidades culturais, quer às propriamente poetológicas de escritores que já então procuravam uma ética militante como princípio estruturador dos seus versos, quer dizer, uma expressão poética regida pela acção, mas não submergida por esta. "Dá-te apenas na acção que é a palavra / mais certa deste mundo", virá a instigar Cinatti em $O$ tédio recompensado. Neste campo, os escritores reunidos em torno da revista de Grigson forneciam-lhe um exemplo que não podia encontrar no então viçoso neorealismo português, cujo empenhamento político e ideológico prejudicava, a seu ver, a dimensão estética da arte. Apesar de os poetas da New Verse terem uma orientação ideológica e política assumidamente marxista, na realidade, tal orientação nunca se sobrepôs à finalidade estética das suas obras, o que terá contribuído para o apreço explícito dos poetas dos Cadernos pela publicação. A poesia social inglesa era, sim, uma poesia de propaganda, mas sem deixar de ser uma propaganda da poesia, pois os seus autores nunca perderam de vista o essencial da condição poética, que é dizer a condição humana. Ao contrário do que acontecia então com uma boa parte da obra produzida pelos neorealistas portugueses, no caso da obra de Day Lewis, MacNeice, Spender e sobretudo Auden, e utilizando uma terminologia bem seniana, a inclinação ético-política dos autores nunca comprometeu a sua posição ético-estética. Por isso Robin Skelton pôde unificar esta geração asseverando que nunca se tratou de "um movimento puramente

\footnotetext{
44 SENA, 1988, p. 147.

${ }^{45}$ RIBEIRO, 1993, p. 8.
} 
socialista", nem sequer social, mas sim de "um movimento da consciência apaixonada"46 - consciência infeliz, sensível e vigilante, diríamos nós. A natureza desta consciência em movimento é nítida nos versos de Stephen Spender que Cinatti escolheu para epígrafe de um dos poemas de Nós não Somos deste Mundo, logo em 1941: "Born of the sun they travelled a short while towards the sun... / And left the vivid air signed with their honour". Trata-se dos versos finais de um dos mais famosos poemas de Spender, composto em 1931, "The truly great":

I think continually of those who were truly great.

Who, from the womb, remembered the soul's history

Through corridors of light where the hours are suns

Endless and singing. Whose lovely ambition

Was that their lips, still touched with fire,

Should tell of the Spirit clothed from head to foot in

song.

And who hoarded from the Spring branches

The desires falling across their bodies like blossoms.

What is precious is never to forget

The essential delight of the blood drawn from ageless springs

Breaking through rocks in worlds before our earth.

Never to deny its pleasure in the morning simple light

Nor its grave evening demand for love.

Never to allow gradually the traffic to smother

With noise and fog the flowering of the spirit.

Near the snow, near the sun, in the highest fields

See how these names are fêted by the waving grass

And by the streamers of white cloud

And whispers of wind in the listening sky.

The names of those who in their lives fought for life

Who wore at their hearts the fire's center.

Born of the sun they traveled a short while towards the sun,

And left the vivid air signed with their honor. ${ }^{47}$

"The truly great" constitui porventura, ao lado dos magníficos "Musée des Beaux Arts" e "The massacre of the innocents" de Auden

\footnotetext{
${ }^{46}$ SKELTON, 1964, p. 36.

${ }^{47}$ SPENDER, 1990, p. 30.
} 
- que Jorge de Sena viria a traduzir e a publicar na Árvore -, o melhor exemplo do modo como esta geração não sacrificou nunca a finalidade estética da poesia a fins ideológico-políticos particulares. Tratou-se, pelo contrário, de cantar a condição humana em tempos de cólera - entre a Guerra Civil de Espanha e a Segunda Guerra Mundial -, sem nunca perder de vista a essência da condição poética, demonstrando que o escritor empenhado não tinha que se tornar um escritor penhorado. Em 1935, dando configuração retórica a esta poética, Auden defenderia a produção de uma poesia fundada na parábola, o que, a vários títulos, terá agradado ao católico Ruy Cinatti:

Não se pode dizer às pessoas o que devem fazer, só pode contar-se-lhes parábolas; e isso é o que a arte é realmente, histórias particulares de pessoas e experiências particulares, das quais cada um de acordo com as suas necessidades imediatas e peculiares pode tirar as suas próprias conclusões. ${ }^{48}$

A parábola foi para Auden uma retórica e uma poética, levando-o mesmo a distinguir, numa tipologia muito pessoal, dois tipos de arte, "a arte fuga, pois o homem precisa da fuga como de comida e de sono profundo, e a arte parábola, aquela arte que ensinará o homem a desaprender o ódio e a aprender o amor". ${ }^{49} \mathrm{O}$ valor da obra de Auden para Cinatti, bem notório nas "Horas canónicas" de Memória Descritiva ${ }^{50}$ residiu tão só naquilo que Edward Mendelson designaria por "a tarefa do momento presente", classificando-a como o "assunto contínuo" da poesia de Auden. ${ }^{51}$ Com uma particularidade primordial: para Auden, a relação do poeta com a história, quer dizer, a presença do poeta no mundo, fundou-se sempre numa visão ininterrupta da história, em que os descontentamentos antigos sobrevivem em formas contemporâneas, e estas naqueles, como aliás se pode verificar nessa súmula que é a fusão de Herodes e Hitler num "massacre dos inocentes" produzido e publicado nos anos do Holocausto. Representante

\footnotetext{
${ }^{48}$ AUDEN, 1935, p. 18-19.

${ }^{49}$ AUDEN, 1935, p. 20.

${ }^{50} \mathrm{O}$ poema de Cinatti, que viria a integrar o volume Memória Descritiva, em 1971, foi divulgado três anos antes, nas páginas da revista $O$ Tempo e o Modo. Na biografia do poeta, Peter Stilwell admite mesmo que Cinatti tenha travado conhecimento directo com Auden, visto que se encontrava em Oxford na altura em que Auden era professor de Poesia naquela universidade (STILWELL, 1995, p. 293, 345).

${ }^{51}$ MENDELSON, 1990, p. ix.
} 
máximo de uma geração, conhecida por “Auden's Country”, que pela escrita fez "vibrar a corda mais profunda da humanidade", porque soube converter o seu presente num instante intemporal, Auden constitui sem dúvida, na época em que Cinatti dava os seus primeiros passos literários, o exemplo mais consumado de como o fundamento ético da poesia podia salvar, e não sacrificar, a sua dignidade estética, "sem a qual as palavras nada podem contra o tempo". ${ }^{2}$

\section{Referências}

ANDRADE, Eugénio de. Rosto precário. Porto: Limiar, 1979.

ANDRESEN, Sophia de Mello Breyner. Obra Poética, I. Lisboa: Caminho, 1999.

AUDEN, Wystan Hugh. Psychology and Art Today. In The Arts Today. London: John Lane The Bodley Head, 1935.

CARLOS, Luís Adriano e FRIAS, Joana Matos. A Poesia É só Uma ou As palavras contra o tempo. Introdução a Cadernos de Poesia, reprodução facsimilada. Porto: Campo das Letras, 2004.

CARLOS, Luís Adriano e FRIAS, Joana Matos (Org.). Cadernos de Poesia: Publicação em Fascículos, 115. Lisboa: 1940/1953. Reprodução fac-similada. Porto: Campo das Letras, 2004.

CINATTI, Ruy. Archeologia ad Usum Animae. Lisboa: Presença, 2000.

CINATTI, Ruy. Cartas a um Vanguardista sobre a arte e a vocação literária: I. O Jornal da Mocidade Portuguesa. Lisboa, 15 jul. 1939.

CINATTI, Ruy. Estudos, Ensaios e Documentos, IV: Explorações Botânicas em Timor. Lisboa: Junta de Investigações Coloniais, 1950.

CINATTI, Ruy. Obra Poética. Organização e prefácio de Fernando Pinto do Amaral. Lisboa: Imprensa Nacional/Casa da Moeda, 1992.

CLAUDEL, Paul. Introduction à un poème sur Dante. In: Positions et Propositions: Art et Littérature. Paris: Gallimard, $19 \overline{38}$.

GUIMARÃES, Fernando. Imaginação e intelectualização: Ruy Cinatti, Sophia Andresen, Eugénio de Andrade e Jorge de Sena. In: Linguagem e Ideologia. Porto: Lello Editores, 1996.

${ }^{52}$ Ver CARLOS; FRIAS, 2004. 
HUSSERL, Edmund. Idées Directrices pour une Phénoménologie (Ideen zu einer Reinen Phänomenologie und Phänomenologischen Philosophie, 1913). Paris: Gallimard, 1950.

HUSSERL, Edmund. La Crise des Sciences Européennes et la Phénoménologie Transcendentale (Die Krisis der europäischen Wissenschaften und die transzendentale Phänomenologie, 1954). Paris: Gallimard, 1976.

JESUS, Eduíno de. Os 'Cadernos de Poesia' têm vinte anos. Rumo, 46. Lisboa: dez. 1960.

KELKEL, Arion L. e SCHÉRER, René. Husserl. Lisboa: Edições 70, 1982.

KIM, Tomaz. Em cada dia se morre.... Lisboa: Edição do Autor, 1939.

LÉVINAS, Emmanuel. Le Temps et l'Autre. Paris: PUF, 1996.

LÉVINAS, Emmanuel. Totalidade e Infinito (Totalité et Infini, 1980). Lisboa, Edições 70: 1988.

LOURENÇO, Jorge Fazenda. Notas para uma arqueologia de Ruy Cinatti. Posfácio a Ruy, CINATTI. Archeologia ad Usum Animae. Lisboa: Presença, 2000.

MÉNARD, René. La Condition Poétique. Paris: Gallimard, 1959.

MENDELSON, Edward. Preface a W. H. AUDEN. Selected Poems. Nova Iorque: Vintage Books, 1990.

MERLEAU-PONTY, Maurice. Le héros, l'homme. In: . Sens et NonSens. Paris: Éditions Nagel, 1963.

MERLEAU-PONTY, Maurice. Le Visible et l'Invisible: Suivi de Notes de Travail (1964). Paris: Gallimard, 1988.

MERLEAU-PONTY, Maurice. Phénoménologie de la Perception. Paris: Gallimard, 1945.

MONTEIRO-GRILLO, J. T. Prefácio a T. S. ELIOT. Ensaios de Doutrina Crítica. Lisboa: Guimarães Editores, 1997.

MONTEIRO-GRILLO, J. T. Uma Introdução à Moderna Poesia Inglesa (1914/1939). Sep. da Revista da Faculdade de Letras de Lisboa, Lisboa, Tomo XVII, 1, 1951.

NOVALIS. Fragmentos. Lisboa: Assírio \& Alvim, 1992. 
RIBEIRO, Maria Margarida de Sá Calafate. Ruy Cinatti em Trânsito. Dissertação de Mestrado - Universidade Nova de Lisboa. Lisboa: 1993. RILKE, Rainer Maria. Os Cadernos de Malte Laurids Brigge. Porto: O Oiro do Dia, 1974.

SARAIVA, Arnaldo. Os Cadernos de Poesia têm vinte anos: ouvindo Ruy Cinatti. Rumo, Lisboa, n. 46, dez. 1960.

SARTRE, Jean Paul. La Responsabilité de l'Écrivain. Vendôme: Verdier, 1998.

SENA, Jorge de. Cadernos de Poesia. In: Portuguesa III. Lisboa: Edições 70, 1988. p. 48.

SENA, Jorge de. Peregrinatio ad Loca Infecta. In: . Estudos de Literatura Lisboa: Edições 70, 1989. p. 76.

SENA, Jorge de. Prefácio da primeira edição. In: .Poesia I. Lisboa: Edições 70, 1988.

SENA, Jorge de. [Carta de 12-5-1942 (para Ruy Cinatti)]. Colóquio/ Letras, Lisboa, n. 80, [s.p.], jul. 1984.

SKELTON, Robin (Ed.). Poetry of the Thirties. London: Penguin, 1964. SOUSA, João Rui de. Uma palavra de fidelidade e de movimento. Jornal de Letras, Artes e Ideias, Lisboa, n. 37, p. 12, 20 out. 1992.

SPENDER, Stephen. Collected Poems 1928/1985. London: Faber \& Faber, 1990.

STILWELL, Peter. A Condição Humana em Ruy Cinatti. Lisboa: Presença, 1995.

TZARA, Tristan. Le Surréalisme et l'Après Guerre. Paris: Les Éditions Nagel, 1966. 